\title{
CRITICAL REVIEW OF FORMATIVE ASSESSMENT PRACTICES IMPLEMENTED IN ENGLISH LANGUAGE LEARNING PROGRAMS IN SINDH
}

\author{
Syed Usman Hashmi ${ }^{1 *}$, Syed Qaiser Hussain ${ }^{2}$, Tahira Adeel Zaman ${ }^{3}$, Samra Arshad $^{4}$, Naeem Akhtar ${ }^{5}$ \\ ${ }^{1 *}$ MS Educational Leadership and Management, Shaheed Zulfikar Ali Bhutto Institute of Science and Technology, Pakistan; \\ ${ }^{2,5}$ Assistant Professor, Shaheed Zulfikar Ali Bhutto Institute of Science and Technology, Pakistan; ${ }^{3}$ Lecturer, Shaheed \\ Zulfikar Ali Bhutto Institute of Science and Technology, Pakistan; ${ }^{4}$ Curriculum Advisor, Pearson Education, Canada. \\ Email: ${ }^{1 *}$ syedusmanhashmi@gmail.com, ${ }^{2}$ toqaiser@gmail.com, ${ }^{3}$ tahirabaig3@gmail.com, ${ }^{4}$ symraarshad@ hotmail.com, \\ 5drnaeem884@gmail.com
}

Article History: Received on $22^{\text {nd }}$ May 2021, Revised on 30 ${ }^{\text {th }}$ May 2021, Published on $4^{\text {th }}$ June 2021

\section{Abstract}

Purpose of the study: The purpose of this study is to explore the merits and demerits of a formative assessment technique used in an English language learning program in Sindh. The teachers teaching the English language to the students of rural Sindh in an English language program implemented a formative assessment technique and in the end, shared their views about the effectiveness of the program.

Methodology: The research is based on a qualitative method. Formative assessment was conducted in a language teaching program in rural Sindh. At the end of the program, 6 male and 12 female teachers, who were selected on purposive sampling method, participated in a focused group interview to share their views about the merits and demerits of the formative assessment technique. The data was analyzed using content and thematic analysis.

Main Findings: The merits of the formative assessment technique used were reported as helpful in identifying the learning gaps, providing constructive feedback, identifying the students' strengths, empowering the teachers, and creating a stressfree assessment. Similarly, the demerits were reported as being time-consuming, unconventional assessment strategies, and creating a lack of professional development to adopting a new strategy.

Applications of this study: Many language teachers regularly implement formative assessment in their language classrooms and are always in search of some good material to make their formative assessment more fruitful and result-oriented. This study will be useful for such teachers. They can benefit from the findings of the study and improvise their method of formative assessment.

Novelty/Originality of this study: The study is one of its kinds using the teachers' perspectives to explore the effectiveness of drawbacks of formative assessment technique. People who have recently joined the teaching fraternity must be inquisitive about various techniques of assessment. This study is going to assist them in not only deciding whether they want to implement formative assessment in class, but it will also prepare them in advance to encounter the limitations of formative assessment and take necessary measures to address these limitations.

Keywords: Formative Assessment, Language Learning, Practices.

\section{INTRODUCTION}

Teaching is very critical because there are various factors involved in teaching, i.e., curriculum design and development, the content of the subject, teaching-learning procedures, assessment, and evaluation. Moreover, teaching further involves the prime factor of education and the educational institution's practices considering the subjects being taught, how to execute the teaching and learning process of those subjects, and eventually the entire process of teaching and learning is then assessed and evaluated by various other strategies that are sometimes productive and outcomes-based, else revision is required (Azis, 2012).

On the other hand, assessment is found to be one of the most essential and influential educational tools for either promoting or demoting student learning and the capacity to perform. For teaching writing and portfolio, assessments and formative assessment play a crucial role (Bader, Burner, Iversen \& Varga, 2019). Assessment can either help the students to perform at their optimum or not perform at all due to stress and anxiety caused because of the exam load, assessments can lead to the active involvement of students (Buyukkarci \& Sahinkarakas, 2021). Similarly, Leenknecht et al (2020) study also focused on students' own motivation in relation to formative assessments and discovered a link between students' motivation and competence towards tasks. However, there may be some issues related to motivation and learning opportunities presented to students (Khajeloo \& co 2021). Presumably, it is one of the most crucial things that teachers can use to help the learning of their students, however, its effectiveness widely depends on the frequency with which it is being implemented (Johnson, Sondergeld \& Wolten, 2019). Additionally, in medical curriculum assessment acts as one of the most vital ingredients as a 
means of providing and ensuring competence, quality-based improvement, and giving and receiving constructive feedback, guidance, and further supervision (Rahman MD \& Majumder, 2015). Even for science subjects, assessment in accordance with science subject-related tasks will prove effective (Alonzo, 2018), and even for math subjects (Amoako, Asamoah \& Bortey, 2019).

Clear vision is also essential in respect to curriculum design and implementation of assessments (Arrafli, 2020) along with 'procession manner' (Cobera, Garcia, Pin \& Montes, 2019) and clearly defined goals (Ahmed, Akhtar \& Aslam, 2020). Though evaluative judgement helps in better comprehension of formative assessments (Panadero et al, 2019). Widiastuti et al (2019) in-depth study with regards to assessment and in particular Formative Assessments, discussed teacher's beliefs and practices, as well as their professional growth, plays a pivotal role. It is about 'closing the gap' (Egelander \& Riese 2020). For teachers, factors, internal or external, influence their take on assessments (Yan, Li, Panadero, Yang, Yang \& Lao, 2020).

Assessment in researchers' language is defined in various ways. The very common understanding of assessment states that with the help of assessment gathering of data and evidence that is based on the performance of students is easier and accessible for future references in terms of further development and progression (Azis, 2012). It "involves making decisions about what is relevant evidence for a particular purpose, how to collect the evidence, how to interpret it and how to communicate it to intended users" (Harlen, 2005, p. 207), as mentioned in Azis (2012). More specifically, Hattie and Timperley (2007), defined assessment as an "activity used to assess a student's level of proficiency".

Additionally, this study looks closely at one of the rubrics being used to assess students (ages 13-16) studying English as Second Language (ESL) for two years in an English language learning program. The rubric of formative assessment is developed by one of the implementers of this English language program in Sindh, Pakistan. Formative Assessments do play an important role in language learning (Ibragimona, 2021).

The study aimed to answer the following research questions.

1. What are the merits of assessing students through formative assessment?

2. What are the demerits of assessing students through formative assessment?

\section{LITERATURE REVIEW}

\section{Assessment}

For the past couple of decades, there has been a change observed in terms of the teaching practice of educationists and policymakers working in the capacity of teaching and educating, i.e., from 'the culture of testing' to 'culture of assessment'.

The so-called culture of testing is distinguished by the typical tests being conducted, mostly based on Multiple Choice Questions (MCQs) that mainly caters facts, memorization, and the ability to check how much one can remember.

The culture of testing is characterized as standardized tests, MCQs based that focuses more on remembrance, memorization, and the ability to determine how much a student can retain the information. Progressive testing, based on learning, is widely used by teachers (Covitt, Gunkel, Caplan \& Syswerda, 2018).

Tests are always considered to be the strategy of checking the student's overall cumulative way of learning. Tests are conducted towards the end of the term, course, or program. Particularly, to judge and weigh the learning of the students that were presented or taught in the form of lectures or books. Moreover, tests are also considered a good way to certify a specific individual by achieving so many grades/positions, etc. The major factor of quality checking is to know and label that a particular student possesses the true knowledge and is stepped ahead from others because of clearing/passing that particular benchmark - so-called the 'Test' (Gulikers, Sluijsmans, Baartman, \& Bartolo, 2008).

The most relevant and debatable question: 'Is it summative i.e., learn and take the test, or formative i.e., assess first or in the middle and learn accordingly? Though, Assessments, whether formative or summative, have importance (Gallardo, 2020).

An explicit demarcation is made between summative and formative assessments. Summative that is self-explanatory with the work itself that to judge the student towards the end of the teaching-learning tenure and then grade the student for reporting purposes. On the contrary, the latter has the objective of making learning easier in terms of identifying the gaps, filling them with the help of learning from the instructors through re-learning and other alternate strategies that can help the student to perform better (Rahman MD \& Majumder, 2015).

As Baranovskaya (2017) stated "The prime purpose of classroom assessments is to allow students to demonstrate/present their learning to share and learn from each other, rather than identifying the mistakes and highlighting them and then discouraging the student. It is inevitable to say that the emphasis of assessment is on various aspects of instruction and learning outcomes. Student's Self-Regulated learning bases assessments tend to increase and enhance students' learning (Granberg, Palm \& Palmberg, 2021). 
Assessment is a very significant part of constructive learning, improving and developing processes. Well-structured and controlled assessments certainly help in scaffolding students to apply and make use of their ability that they have been able to learn based on a formative assessment. A very recognized and productive strategy i.e., providing constructive feedback based on the assessment outcomes' delivers students with strong and additional data/information in the certain area where improvement is required.

In this way, the teacher can very clearly assess the learning and then proceed ahead with the objective in mind of assessing for learning. Furthermore, by using the interesting and engaging formative assessment strategies teachers can break the monotony and make learning fun and exciting, and towards the end show the students the level of their success and improvement (Baranovskaya, 2017). Assessment practice co-relate in some form with the self-efficacy beliefs of teachers (Myyry, et al, 2021).

The very initial application of Formative Assessment (FA) is used in the attempt of developing an instructional process. In this method, teachers assess a student's performance during instructional hours that will occur in phases. This strategy is adopted to supervise student's learning for further improvement and feedback throughout the course (Ozan \& Kincal 2018). This is spread throughout the period about the gradual growth and improvement. Some of the examples of FA include Students Observations, learning from peer reviews, Presentations, Think-Pair and then Share, Focused Group Discussions, Constructive Feedback (Prasanthi \& Vas, 2019). Timely feedback from teachers improves student's academic proficiencies (Kyaruzi, Strijbos, Ufer \& Brown, 2019).

Summative Assessment (SA) is to measure the achievements of pupils towards the conclusion of the instructional period. Benefits in a long stretch can be examined of the students who have been attending the course/program. Some of the examples of SA include Mid examinations, End University exams (Prasanthi \& Vas, 2019).

After browsing and getting to know about the two above-mentioned assessment types i.e., FA and SA, it is not a final verdict to use this one or that one, however, a teacher has to choose a productive way to assess because this is a crucial part of learning. Also, deciding the productive and better strategy can be fruitful and outcomes-based in the longer run (Stăncescu \& Drăghicescu, 2018). Thus, it is important to observe through this research how formative assessment can be helpful in terms of observations and making the required revisions for better and productive learning outcomes.

Both of the above-mentioned assessments can be a good learning source considering the approach of the assessor. SA should not be made challenging in terms of learning and assessing processes. On the other hand, FA should be incorporated with or without SA keeping in mind student's motivation, encouragement, self-learning throughout all levels and stages of the assigned curriculum of an English Language Course (Rahman MD \& Majumder, 2015).

It is observed that well-structured assessment strategies certainly have a higher percentage of impact on student's performance and achievements. Higher education is constantly striving to incorporate effective assessment strategies for enhancing the overall learning process (Sewagegn, 2019). However, classroom-based assessments are teacher-mediated, context-based and students' involvement can be noticed (Abeywickrama, 2021).

Previous studies have shown significant improvement in student's learning where FA is used by educators as one of the assessment strategies. However, this is also found that FA strategies are missing from many classrooms (Cullinane, 2011).

\section{Formative Assessment}

Instructive specialists endorse the application of FA compared to the SA. FA does not serve to be a certification but delivers responses about the knowledge and instruction procedures that could be important in the long run for both educators and learners.

By using effective and productive FA strategies, students can improve their motivation level and also demonstrate their learning better (Baranovskaya, 2017). FA is also being carried out at various Medical schools and they have made FA mandatory and crucial because of its benefits (Carrillo-de-la-Peña, Bailles, Caseras, \& Martínez, 2009).

According to Prasanthi \& Vas (2019) "Formative Assessment is used in the first attempt of developing instruction. In this method, assessing a student's performance during instruction, and usually occurs at regular intervals throughout the instruction process is done. It is used to monitor student learning and to provide feedback during the course. It is used for finding growth over time".

The purpose of Bloom regarding FA was to ensure checks in the form of feedback at various levels of learning. Along with this SA was used to check the overall performance at the end (Bennett, 2011).

It is crucial to understand that FA should be incorporated somewhere at the centre of the learning process, even if it is not being used at the initial or the end, no matter whatever the situation comes across in a teaching-learning situation. 
FA helps in keeping track of student's learning in a subjective manner but that is very encouraging and helps is an overall improvement to see student's achievements and discover new ways in learning. FA is quite beneficial in providing comments to the pupils, it is a good learning opportunity for the teachers as well. Moreover, one more crucial purpose of FA is that it helps the educators to keep a track of their own teaching-learning objectives preferred to be achieved at the step-bystep process (Hamidi, Shaffiei, Sarif, \& Ashar, 2013).

In the last couple of years, there has been a lot of study on how to use FA strategies in English Language programs and kept revising, if required as per the milestones of curriculum (Pastore \& Pentassuglia, 2014). One of the most effective strategies being currently used and has been proven effective as well is 'Constructive Feedback'. This strategy has been proved to be extremely beneficial in terms of teaching-learning outcomes in either written or oral form. This strategy cannot be applied in SA to extend to improve learning that way it can be done in FA. Feedback has proven to be very beneficial for both students and teachers, providing step-by-step guidance and gradual progression in the learning process (Voinea, 2018).

Formative assessment through feedback and feed-forward promotes learning (Koka, Jurāne-Brēmane, \& Koke, 2017).

Formative Assessment can be a means for teachers' professional development and can be fruitful (Khan, Zaman \& Saeed 2020); with guidance and set materials (Wylie \& Lyon 2020), training to use materials effectively Low et al 2018), use based on contextual knowledge (Vogt et al 2020), be a link between teachers and students perceived knowledge regarding the subjects (Wafubwa et al 2021), and can be a means to also evaluate teachers' evaluation and observation (Alexandratos, Papachristos, Mangli, 2021).

Implementing formative assessment requires targeted tools (Xiang, Yum \& Lian 2020), and must develop new instructional practices (Heredra 2020) and can improve scientific instructions (Cisterna \& Gotwals, 2018).

E-learning platform (Irving 2020) and technology mean is also utilized, especially during the covid pandemic (Antonova \& Tykhera, 2021), hence mobile-based formative assessments can be utilized (Hasan, Islam \& Shuchi, 2021), and online-based assessments (Ogange, Agak, et al 2018) though they may have some disadvantages as higher education student can face the certain limitation of bad internet connection, illegal means to complete test and not enough time to complete the task ( $\underline{\text { Simon, }}$ 2019).

The feedback enables the students to learn regarding their strengths and weaknesses. These points are not highlighted in SA because SA focuses more on overall scoring and grading. The identification of strengths and weaknesses of a student helps in planning the learning strategies, various other strategies to improve the learning of a student, and how to address the learning gaps in the most effective manner possible. It also helps to address mistakes, how to subjugate them with effective learning progression, wrong and right perceptions are welcome regarding the understanding and prior cognitive development of a student (Voinea, 2018).

One more important and current issue regarding the assessment of skills being discussed through literature, because learning and then using a language is a skill that is being assessed through the FA rubric in this research paper.

A fundamental question is: Is the assessment in Higher Education a process or a product of a skill? Here, teaching is considered to be the process and learning is the product (Cimatti, 2016). After studying and knowing about various assessment strategies, they all seem to have their own merits and demerits. However, there is not any single assessment procedure or a strategy that can fulfil the overall requirement of an English Language Program. Studies show that the use of various and effective (considering the interest of students as well) assessment strategies can yield better learning outcomes and opportunities to have an exposure that helps the students to cater to various assessment needs (Sewagegn, 2019).

Needless to say, that assessment and learning process goes hand-in-hand, so just like learning is being moulded and devised to cater to the needs of the students, the same goes for assessment to be made learner-centred and practice-orientated.

An assessment should be 'tailored-for-learning' and it should enable to extend and facilitate learning for every student possible so that students are fearless to make mistakes and are motivated to learn more than to score more. Teachers should be trained to consider not just what they are assessing, and how they are assessing, but also why (rationale) they are assessing, because this rationale will make their assessment worth assessing for their students. The obvious response should be to foster and facilitate learning by all possible means (Rahman MD \& Majumder, 2015). Additionally, FA also promotes critical thinking and produces a comprehensive understanding of their ongoing course (Riaz, Yasmin, \& Yasmin, 2016).

\section{METHODOLOGY}

The research used a qualitative research method to carry out the proceedings. The teachers teaching the English language in the program participated in a focused group interview to answer questions regarding the advantages and limitations of formative assessment. 


\section{Sampling Method}

The researcher used a purposive sampling technique for this research.

\section{Sample Size}

18 teachers were selected for the focused group interview. Out of these 18 English language teachers, 6 were males and 12 were females.

\section{FINDINGS AND INTERPRETATION OF THE DATA}

\section{Merits of the Formative Assessment's Rubric}

The responses that were collected in the focused group interview were about the merits and demerits of formative assessment being used in the English language learning Program in Sindh. In the analysis, the received data gave the following themes.

\section{Identification of Learning Gaps}

The most common theme that came out from the responses was the identification of the learning gap in students. This is possible because teachers observe the students very keenly and vigilantly throughout the entire month and they are able to observe in which area that particular student requires improvement. After diagnosis, a prescription is then suggested through feedback, or a different strategy is opted. $1 \mathrm{~F}$ said, "Be aware of areas where students are lacking". A similar response of 4M saying, "...able to know what are the areas where a student needs to work hard". Furthermore, F5 said, "...identify the target areas that need work which ultimately helps a teacher to figure out what teaching strategies should be adopted". 10F said, "We can keep a check on students' learning gaps and then how to develop further learning". A very similar response of 12F, "It helps identify gaps in learning and improves learning". There were 5 participants out of 18 who were comfortable sharing that they are able to identify the learning gaps of the students with the help of the rubric of formative assessment.

\section{Helpful in providing constructive feedback}

With the help of formative assessment rubric being used in the English language learning Program - participants said that after identifying the learning gaps they can provide feedback to the students so that they can better learn and improve their performance in that specific area where they are lacking. 2F said, "Focused and targeted feedback can be given to the students with the help of this rubric". 1M comments, "Good tool for providing feedback to students...".

\section{Students' Strengths}

Another most common theme that came out from the responses was that the teachers can identify the strengths of the students with the help of this particular formative assessment rubric. $1 \mathrm{~F}$ said, "We come to know about the ability and learning strength of students", she further added, "Also know how students are in active participation". 3F said something similar, "It lets the teacher know where their students stand", adding more she said, "...enables the teacher to be specific while observing students' every skill”. 1M comments by saying, "Easy to track the performance of individual students...". Moreover, 4M said, "When we know the strengths...we can assign leadership and challenging tasks to those students who excel". 5M said, "...helps the students to understand better way".5F adding, "...useful to monitor the student's level of learning, strengths...". 6M specifying, “...identifies students' talent, confidence, interest...”.

\section{Teachers feel empowered}

An interesting response that came out was that the teachers felt empowered by using the rubric of formative assessment because they were being consulted about the student's progress and performance and later on teachers advised accordingly how to move ahead for further development and progressions. $11 \mathrm{~F}$ said, "...helps us to check whether the teaching strategies we are employing are effective or not...", she further added, "We feel empowered by being given the liberty to first assess and then being given a free-hand to devise our activities/lessons accordingly".

\section{Stress-free assessment}

The most important factor for which this rubric was made part of the assessment strategy was to ensure that the students are not at all under any kind of stress/pressure while being assessed. During the lessons, teachers are observing and being very vigilant in terms of monitoring student's learning and developing a congenial environment that fosters learning. In this situation a student feels relaxed and can perform naturally better because he/she knows that there are no marks, it's just a matter of performance and on that basis, he/she will move ahead. 8F remarked, "Students don't feel burdened as they don't have to meet any standardized criterion or appear for any examination", a similar comment of 7F adding, "It also lessens the anxiety students usually have at the end of the term". 


\section{Demerits of Formative Assessment's Rubric}

Under the head of demerits of formative assessment's rubric, some demerits came out from the questionnaire survey.

\section{Time Consuming}

One of the responses that came out was that the rubric of formative assessment consumes the time and energy of the teachers as compared to the other assessment strategies. Since there is no paper-pen testing towards the end of month/quarter/course while following the rubric, hence teachers are observing the students throughout the program and as a matter of fact in every class, so that teachers do not miss any crucial development or learning gap, etc. in terms of teaching-learning that leads to improvisation. $2 \mathrm{~F}$ and $5 \mathrm{~F}$ both said, "It is time-consuming and we are always alert because of this rubric". Some more responses adding to the theme $7 \mathrm{~F}$ said, "It consumes more time and the results are subjective depending on teachers' opinions about the students". The last comment of $12 \mathrm{~F}$ adds, "It can be very time-consuming at times".

\section{An Unconventional Assessment Strategy}

One of the responses of 4F, "Students may feel over relaxed and take the learning process for granted because of nontraditional ways of being assessed". She also added, "A completely different way of assessing in English Language classes ... never used before, it took some time for me to get used to this rubric".

\section{Lack of Professional Development to Adopting a New Strategy}

One more response that was observed was that this alternate strategy or a new strategy of assessment should have been given some time and training to overcome the challenges of using and applying it in ESL/EFL classes. One of the responses, 12F said, "Teachers may lack training or professional development to use it successfully and productively".

\section{DISCUSSION}

This critical review of one of the rubrics being used in Formative Assessment provides an overview of formative assessment strategy based on a rubric pertinent to the English language course.

This study will enable the reader to come across the conclusion of how various techniques of Formative Assessment can be used and applied in English Language Classrooms.

Considering the previous studies this issue has not been highlighted up to this extent that caters to Formative Assessment strategies and approaches. The study steadily displayed only assessment "for learning" rather than "of learning" is a better approach towards learner's autonomy and overall motivation cum encouragement that uplifts the moral of a student.

A categorization of phases was developed to set up the situation that developed into the following levels: setting goals for students in efforts/participation (Part 1 of rubric) that helps in improving behavior; the assessment of each language component. (Part 2 of rubric); guidance/feedback/advice of the educator while thoughts and delivery; pure orientations if pupil's desire additional evaluation; educator visions into pupil's inspiration. This entire process of learning-sharinggrowing-sharing-learning becomes a cyclical process in which a student performs at its best, and not being labelled due to scores/grades.

\section{CONCLUSION}

This study shows that the procedure used to carry out the research proved good results. It provides an explicit approach of using Formative Assessments and their various strategies including one of the rubrics that is being used throughout this paper. With the help of the thematic analysis carried out due to the qualitative method will be a good treat for the readers to learn and then apply accordingly. It outlines the association between formative assessments, student's performance, and improvement through constructive feedback.

The writers claimed that the formative assessment rubric plays a foremost part in ELT and discovered various themes of merits and demerits of the formative assessment rubric as one of the strategies which they embedded in the curriculum.

The study of English Language Teaching based on assessment techniques and its applications have proved to be beneficial in terms of helping the readers and especially the teachers to adapt/adopt the instruments being used in their contexts. This adds value to examine if the same instrument is used in another setting and then analyze and evaluate the findings based on the same instrument but used in a different setting. My detailed study on Formative Assessment and using a rubric used for selfassessment, constructive feedback, and learning progression has a lot of benefits that nurtures learning in a burden-free environment and enables the students to progress further.

Additionally, a very crucial variable has been left in terms of investigation in this paper that is 'How Formative Assessment strategy while using a rubric is having an effect on student's motivation level?' This opens an avenue of further exploration to examine and evaluate for a wider range of audiences based on the Formative Assessment strategy. 


\section{LIMITATIONS}

The study limits itself to assess the effectiveness of formative assessment to the teachers teaching to young learners. However, assessment is a process that is employed generally in every language teaching class. Therefore, this study did not cover other language learning classes and their language teachers. Similarly, this study focuses on one of the parts of Sindh. The sample, therefore, represents the opinions of teachers teaching in only one community.

\section{RECOMMENDATIONS}

The authors of this research would like to recommend that the formative assessment rubric should be adopted to carry out future research considering the following proceedings and areas.

1. It can be used in a different area of Pakistan besides the Sindh region to check its effects and applicability.

2. For another course of ESL/EFL where the students could be of different age groups.

\section{AUTHORS' CONTRIBUTION}

Syed Usman Hashmi: Mr. Usman came up with the idea of this research and wrote data analysis of the paper, conclusion, and recommendation of the paper.

Syed Qaiser Hussain: Mr. Qaiser designed the methodology and wrote the discussion of the paper.

Tahira Adeel Zaman: Ms. Tahira drafted the literature review section of the paper.

Samra Arshad: Ms. Samra wrote the introduction of the paper.

Dr. Naeem Akhtar: Dr. Naeem gave the final feedback on the paper and relevant changes were brought according to his expert opinion.

\section{REFERENCES}

1. Abeywickrama, P. (2021). Classroom Assessment Practices In An L2 Oral Skills Class. European Journal of Applied Linguistics and TEFL, 10(1), 45-61.

2. Ahmed, U., Akhtar, N., \& Aslam, R. (2020). Formative assessment in elementary English classroom: a case study of semi-government organization of Pakistan. Academic Research International, 11(2), 1-9.

3. Alexandratos, G., Papachristos, K., Manafi, I., \& Alexandratou, V. (2021) Critical teaching observation for formative assessment purposes. Scientific Educational Journal, 9(1).

4. Al-Mahrooqi, R. I., \& Denman, C. (2018). Alternative Assessment Edition: 1st (pp.4851-4856). John Wiley \& Sons. https://doi.org/10.1002/9781118784235.eelt0325

5. Alonzo, A. C. (2018). An argument for formative assessment with science learning progressions. Applied Measurement in Education, 31(2), 104-112. https://doi.org/10.1080/08957347.2017.1408630

6. Amoako, I., Brembong, D. A., \& Bortey, J. (2019). Knowledge of formative assessment practices among senior high school mathematics teachers in Ghana. Open Journal of Social Science Research, 3(3), 8-13.

7. Antonova, K., \& Tyrkheeva, N. (2021). Formative assessment of critical reading skills in higher education in Russia in the context of emergency remote teaching. Journal of Teaching English for Specific and Academic Purposes, 137-148.

8. Arrafii, M. A. (2020). Towards Formative Assessment: Exploring English Teachers' Conceptions and Practices of Assessment in Indonesia (Doctoral dissertation, University of Leicester).

9. Azis, A. (2012). Teachers' Conceptions And Use Of Assessment In Student Learning. Indonesian Journal of Applied Linguistics, 41-51. https://doi.org/10.17509/ijal.v2i1.72

10. Bader, M., Burner, T., Hoem Iversen, S., \& Varga, Z. (2019). Student perspectives on formative feedback as part of writing portfolios. Assessment \& Evaluation in Higher Education, 44(7), 1017-1028. https://doi.org/10.108 0/02602938.2018.1564811

11. Baranovskaya, T. (2017). Assessment and Evaluation Techniques. National Research University Higher School of Economics Journal of Language \& Education, 30-38. https://doi.org/10.17323/2411-7390-2017-3-2-30-38

12. Bennett, R. E. (2011). Formative assessment: a critical review. Assessment in Education: Principles, Policy \& Practice, 18(1), 5-25. https://doi.org/10.1080/0969594X.2010.513678

13. Buyukkarci, K., \& Sahinkarakas, S. (2021). The Impact of Formative Assessment on Students' Assessment Preferences. The Reading Matrix: An International Online Journal, 21(1).

14. Carrillo-de-la-Peña, M. T., Bailles, E., Caseras, X., \& Martínez, A. (2009). Formative assessment and academic achievement in pre-graduate students of health sciences. Advances in Health Sciences Education 14(1), 61-67. https://doi.org/10.1007/s10459-007-9086-y 
15. Cimatti, B. (2016). Definition, Development, Assessment Of Soft Skills And Their Role For The Quality Of Organizations And Enterprises. International Journal for Quality Research.

16. Cisterna, D., \& Gotwals, A. W. (2018). Enactment of ongoing formative assessment: Challenges and opportunities for professional development and practice. Journal of Science Teacher Education, 29(3), 200-222. https://doi.org/10.1080/1046560X.2018.1432227

17. Cobeña, G. T. B., García, L. A. P., Pin, S. C. S., \& Montes, L. C. Z. (2021)The Formative Assessment as Systematic Practice in Higher Basic Education Students. International Research Journal of Management, IT and Social Sciences, 8(2), 132-140. https://doi.org/10.21744/irjmis.v8n2.1100

18. Covitt, B. A., Gunckel, K. L., Caplan, B., \& Syswerda, S. (2018). Teachers' use of learning progression-based formative assessment in water instruction. Applied Measurement in Education, 31(2), 128-142. https://doi.org/10.10 $0 / 08957347.2017 .1408627$

19. Cullinane, A. (2011). Formative Assessment Classroom Techniques. National Centre for Excellence in Mathematics and Science Teaching and Learning, 1-4.

20. Dongfang, W., Yuting, S., \& Ting, J. (2018). The Assessment of Higher Education Quality from the Perspective of Students through a Case Study Analysis. Frontiers of Education in China, 267-287. https://doi.org/10.1007/s11516$\underline{018-0014-0}$

21. Egelandsdal, K., \& Riese, H. (2020). Never mind the gap: Formative assessment confronted with Dewey's and Gadamer's concept of experience. European Journal of Education, 55(1), 91-104. https://doi.org/10.111 1/ejed.12378

22. Gallardo, K. (2021). The Importance of Assessment Literacy: Formative and Summative Assessment Instruments and Techniques. In Workgroups eAssessment: Planning, Implementing and Analysing Frameworks (pp. 3-25). Springer, Singapore. https://doi.org/10.1007/978-981-15-9908-8_1

23. Granberg, C., Palm, T., \& Palmberg, B. (2021). A case study of a formative assessment practice and the effects on students' self-regulated learning. Studies in Educational Evaluation, 68, 100955. https://doi.org/10.1016 /j.stueduc. 2020.100955

24. Gulikers, J. T., Sluijsmans, D., Baartman, L., \& Bartolo, P. A. (2008). The Power of Assessment in Teacher Education. Springer. https://doi.org/10.1007/978-1-4020-8874-2_13

25. Hamidi, S., Shaffiei, Z., Sarif, S., \& Ashar, N. (2013). Exploratory Study of Assessment in Teaching and Learning. 3rd International Conference on Research and Innovation in Information Systems. https://doi.org/10.1109 /ICRIIS.2013.6716743

26. Harlen, W. (2005). Teachers' summative practices and assessment for learning-tensions and synergies. Curriculum Journal, 16(2), 207-223. https://doi.org/10.1080/09585170500136093

27. Hasan, M., Islam, A. S., \& Shuchi, I. J. (2021). Using mobile-based formative assessment in ESL/EFL speaking. Journal of Languages and Language Teaching, 9(1), 117-125. https://doi.org/10.33394/jollt.v9i1.3449

28. Hattie, J., \& Timperley, H. (2007). The power of feedback. Review of educational research, 77(1), 81-112. https://doi.org/10.3102/003465430298487

29. Heredia, S. C. (2020). Exploring the role of coherence in science teachers' sensemaking of science-specific formative assessment in professional development. Science Education, 104(3), 581-604. https://doi.org/10.1002/ sce. 21561

30. Ibragimova, M. K. (2021). Digital Tools For Formative Assessment. E-Conference Globe, 335-339.

31. Irving, K. E. (2020). Technology-assisted formative assessment. Learning and Performance Assessment: Concepts, Methodologies, Tools, and Applications, 435-453. https://doi.org/10.4018/978-1-7998-0420-8.ch021

32. Johnson, C. C., Sondergeld, T. A., \& Walton, J. B. (2019). A Study of the Implementation of Formative Assessment in Three Large Urban Districts. American Educational Research Journal, 56(6), 2408-2438. https://doi.org/10.310 2/0002831219842347

33. Jonglai, S. A., Pike, M., \& Lamb, M. (2021). Formative Assessment: The Malaysian English Language Primary School Teachers' Pedagogical Beliefs and Values. International Journal of English Language Studies, 3(4), 52-66. https://doi.org/10.32996/ijels.2021.3.4.5

34. Karin Vogt, Dina Tsagari, Ildikó Csépes, Anthony Green \& Nicos Sifakis (2020) Linking Learners' Perspectives on Language Assessment Practices to Teachers' Assessment Literacy Enhancement (TALE): Insights from Four European Countries. Language Assessment Quarterly, 17(4), 410-433. https://doi.org/10.1080/154 34303.2020.1776714

35. Kechagias [Ed.], K. (2011). Teaching and Assessing Soft Skills. Neapolis (Thessaloniki): 1st Second Chance School of Thessaloniki (Neapolis) Str. Strempenioti, 1st and 3rd Gymnasium 56760 Neapolis (Thessaloniki) ISBN: 978960-9600-00-2.

36. Khajeloo, M., Birt, J. A., Kenderes, E. M., Siegel, M. A., Nguyen, H., Ngo, L. T., ... \& Cummings, K. (2021). Challenges and Accomplishments of Practicing Formative Assessment: a Case Study of College Biology 
Instructors' Classrooms. International Journal of Science and Mathematics Education, 1-18. https://doi.org/10.1 007/s10763-020-10149-8

37. Khan, M., Zaman, T. U., \& Saeed, A. (2020). Formative Assessment Practices of Physics Teachers in Pakistan. Jurnal Pendidikan Fisika Indonesia, 16(2), 122-131.

38. Kohler, B., \& Alibegovic, E. (2015). Assessing for Learning. Mathematics Teaching in the Middle School, 424-433. https://doi.org/10.5951/mathteacmiddscho.20.7.0424

39. Koka, R., Jurāne-Brēmane, A., \& Koķe, T. (2017). Formative Assessment in Higher Education: From Theory to Practice. European Journal of Social Sciences Education and Research, 28-34. https://doi.org/10.26417/ej ser.v9i1.p28-34

40. Kyaruzi, F., Strijbos, J. W., Ufer, S., \& Brown, G. T. (2019). Students' formative assessment perceptions, feedback use and mathematics performance in secondary schools in Tanzania. Assessment in Education: Principles, Policy \& Practice, 26(3), 278-302. https://doi.org/10.1080/0969594X.2019.1593103

41. Leenknecht, M., Wijnia, L., Köhlen, M., Fryer, L., Rikers, R., \& Loyens, S. (2021). Formative assessment as practice: the role of students' motivation. Assessment \& Evaluation in Higher Education, 46(2), 236-255. https://doi.org/10.1080/02602938.2020.1765228

42. Low, J., Shahrill, M., Perera, J. S. H. Q., \& Prahmana, R. C. I. (2018, September). Characterising formative assessment practices in the mathematics classes. In Journal of Physics: Conference Series, 1088(1), 012015. https://doi.org/10.1088/1742-6596/1088/1/012015

43. Lungu, S., Matafwali, B., \& Banja, M. K. (2021). Formative and summative assessment practices by teachers in early childhood education centres in Lusaka, Zambia. European journal of education studies, 8(2).

44. Myyry, L., Karaharju-Suvanto, T., Virtala, A. M. K., R Raekallio, M., Salminen, O., Vesalainen, M., \& Nevgi, A. (2021). How self-efficacy beliefs are related to assessment practices: a study of experienced university teachers. Assessment \& Evaluation in Higher Education, 1-14. https://doi.org/10.1080/02602938.2021.1887812

45. Ogange, B., Agak, J., Okelo, K., \& Kiprotich, P. (2018). Student perceptions of the effectiveness of formative assessment in an online learning environment. Open Praxis, 10(1), 29-39. https://doi.org/10.5944/op enpraxis.10.1.705

46. Ounis, A. (2017). The Assessment of Speaking Skills at the Tertiary Level. International Journal of English Linguistics, 7(4), 95-112. https://doi.org/10.5539/ijel.v7n4p95

47. Ozan, C., \& Kincal, R. Y. (2018). The effects of formative assessment on academic achievement, attitudes toward the lesson, and self-regulation skills. Educational Sciences: Theory and Practice, 18(1), 85-118.

48. Panadero, E., Broadbent, J., Boud, D., \& Lodge, J. M. (2019). Using formative assessment to influence self-and coregulated learning: the role of evaluative judgement. European Journal of Psychology of Education, 34(3), 535-557. https://doi.org/10.1007/s10212-018-0407-8

49. Pastore, S., \& Pentassuglia, M. (2014). formative assessment and teachers' practice: implications for educational research and professional development. Education in a Changing Society, 14-18. https://doi.org/10.1518 1/atee.v1i0.658

50. Prasanthi, B., \& Vas, V. (2019). Classroom Assessment Methods And Tools:A Review. International Journal of Research and Analytical Reviews, 94-97.

51. Rahman MD, S., \& Majumder, A. A. (2015). Is it assessment of learning or assessment for learning? South East Asia Journal Of Public Health, 72-74. https://doi.org/10.3329/seajph.v4i1.21847

52. Riaz, F., Yasmin, S., \& Yasmin, R. (2016). Introducing regular formative assessment to enhance learning among dental students at Islamic International Dental College. Journal of Pakistan Medical Association, 65(12), 12771282.

53. Sewagegn, A. A. (2019). A Study on the Assessment Methods and Experiences of Teachers at an Ethiopian University. International Journal of Instruction, 605-622. https://doi.org/10.29333/iji.2019.12238a

54. Simon, W. E. (2019). Evaluation of online formative assessment practices at higher education institutions (Doctoral dissertation, University of Pretoria).

55. Stăncescu, I., \& Drăghicescu, L. M. (2018). the importance of assessment in the educational process - science teachers' perspective. The European Proceedings of Social \& Behavioural Sciences, 753-759. https://doi.org/10.154 05/epsbs.2017.07.03.89

56. Tridane, M., Belaaouad, S., Benmokhtar, S, Gourja, B., \& Radid, M. (2015). The impact of formative assessment on the learning process and the unreliability of the mark for the summative evaluation. Malika Tridane et al. / Procedia - Social and Behavioral Sciences 197, 680-685. https://doi.org/10.1016/j.sbspro.2015.07.058

57. Voinea, L. (2018). Formative Assessment As Assessment For Learning Development. Journal of Pedagogy, 7-23. https://doi.org/10.26755/RevPed/2018.1/7

58. Wafubwa, R. N., \& Csíkos, C. (2021). Formative Assessment as a Predictor of Mathematics Teachers' Levels of Metacognitive Regulation. International Journal of Instruction, 14(1). https://doi.org/10.29333/iji.2021.14158a 
59. Widiastuti, I. A. M. S., Mukminatien, N., Prayogo, J. A., \& Irawati, E. (2020). Dissonances between Teachers' Beliefs and Practices of Formative Assessment in EFL Classes. International Journal of Instruction, 13(1), 71-84. https://doi.org/10.29333/iji.2020.1315a

60. Wylie, E. C., \& Lyon, C. J. (2020). Developing a formative assessment protocol to support professional growth. Educational Assessment, 25(4), 314-330. https://doi.org/10.1080/10627197.2020.1766956

61. Xiang, X., Yum, S., \& Lian, R. (2020). Teachers' self-efficacy and formative assessment of students: Moderating role of school goal structure. Social Behavior and Personality: an international journal, 48(6), 1-13. https://doi.org/10.2224/sbp.9208

62. Yan, Z., Li, Z., Panadero, E., Yang, M., Yang, L., \& Lao, H. (2021). A systematic review on factors influencing teachers' intentions and implementations regarding formative assessment. Assessment in Education: Principles, Policy \& Practice, 1-33. https://doi.org/10.1080/0969594X.2021.1884042 